\title{
Photon Shielding Features of Quarry Tuff
}

\author{
Hector Rene Vega-Carrillo,a, ${ }^{1, \text { Luis Hernandez-Adame }}{ }^{2}$, Karen Arlete Guzman-Garcia ${ }^{3}$, Arturo Agustin Ortiz-Hernandez ${ }^{4}$, \\ Jose Antonio Rodriguez-Rodriguez ${ }^{5}$ and Cesar Antonio Juarez-Alvarado ${ }^{5}$ \\ ${ }^{1}$ Universidad Autonoma de Zacatecas, UA de Estudios Nucleares, Cipres 10, Fracc. La Peñuela, 98068 Zacatecas, Zac., Mexico \\ ${ }^{2}$ Laboratoire de Chimie Physique, UMR 8000-CNRS, Universite' Paris-Sud, 91405 Orsay, France \\ ${ }^{3}$ Universidad Politecnica de Madrid, Dept. Ingenieria Energetica, C. Jose Gutierrez Abascal 2, 28600 Madrid, Spain \\ ${ }_{4}^{4}$ Instituto Politecnico Nacional, Campus Zacatecas, Blvd. El Bote, Zacatecas, Zac. Mexico \\ ${ }^{5}$ Universidad Autonoma de Nuevo Leon, Fac. de Ingenieria Civil, C. Pedro de Alba s/n, San Nicolas de los Garza, NL, Mexico
}

\begin{abstract}
Cantera is a quarry tuff widely used in the building industry; in this work the shielding features of cantera were determined. The shielding characteristics were calculated using XCOM and MCNP5 codes for 0.03, 0.07, 0.1, $0.3,0.662,1,2$, and $3 \mathrm{MeV}$ photons. With XCOM the mass interaction coefficients, and the total mass attenuation coefficients, were calculated. With the MCNP5 code a transmission experiment was modelled using a point-like source located $42 \mathrm{~cm}$ apart from a point-like detector. Between the source and the detector, cantera pieces with different thickness, ranging from 0 to $40 \mathrm{~cm}$ were included. The collided and uncollided photon fluence, the Kerma in air and the Ambient dose equivalent were estimated. With the uncollided fluence the linear attenuation coefficients were determined and compared with those calculated with XCOM. The linear attenuation coefficient for $0.662 \mathrm{MeV}$ photons was compared with the coefficient measured with a $\mathrm{NaI}(\mathrm{Tl})$-based $\gamma$-ray spectrometer and a ${ }^{137} \mathrm{Cs}$ source.
\end{abstract}

\section{Introduction}

Due to the importance for radiation protection the shielding characteristics of man-made or natural occurring materials have been investigated. Thus, different shielding properties of building materials [1-3], ores [4], glasses [5, 6], plastics and polymers [7], Lunar soil samples [8], gemstones, like the Amethyst [9], Boron containing materials [10], alloys [11], nanoparticles of W and polyethylene dispersed in polymer [12], and concrete with different aggregates [13-16] have been reported.

Some of the shielding features include the effective atomic number, the effective electron density, the half value layer, the energy absorption and exposure buildup factors, the linear attenuation coefficient $(\mu)$, and the mass attenuation coefficient $(\mu / \rho)$ for photons.

In the cases of lunar soils the dose reduction and the protection against Galactic Cosmic Rays have been studied [8].

Another important shielding feature includes the materials behaviour against neutrons, thus Singh, Badiger and El-Khayatt [1] reported the shielding features against neutrons of building materials.

Also designed materials, like the Hormirad ${ }^{\mathrm{TM}}$, which is a high-density concrete has been evaluated as neutron shielding using experimental procedures with isotopic neutron sources and through Monte Carlo calculations
[17]. Another designed material, known as NGSconcrete, polymers and standard cements mortars have been studied in their shielding features $[18,19]$. In these studies, the half value layer and the ten value layer were evaluated.

The shielding characterization has been carried out through measurements, calculations or combining both procedures.

Tuffs are volcanic rocks made of an ash matrix with grain sizes ranging from fine clay minerals up to siltsized material, containing lithic, vitric and crystal clasts. Tuffs are formed from pyroclastic flow, surge and fall deposits that combined with the primitive magma features, the deposition and compaction of the emitted material and the post depositional processes concur to find tuffs with different textures, and petrographic and chemical compositions [20].

Volcanic tuffs minerals have been proposed to improve the indoor environments reducing the microbial contaminants and the airborne fungal carcinogens [21].

Quarry tuffs are mostly soft and porous rocks used as building stones and for artwork because can be easily cut and reworked. Volcanic tuff stones are in different colours, they are used as covering materials for insulating and ornamental purposes on the exterior and interior of buildings [22-25].

\footnotetext{
${ }^{\mathrm{a}}$ Corresponding author: fermineutron@yahoo.com
} 
In the construction industry the quarry tuff (cantera) is used to coat the interior and exterior wall surfaces of buildings and houses avoiding the use of paint. Its use is part of the Mexico's stone heritage being present in preHispanic, Colonial and modern architecture [26]. A radiometric analysis of this material from Turkey has been reported $[24,25]$, being in mostly of cases safe.

In Mexico, there are several cities where the cantera is widely used, it is found in prehispanic constructions, cathedrals, and modern buildings and houses. Cantera is used and the main construction material or as decorative item attached to the walls.

In several facilities having $\mathrm{x}$-ray machines or sealed radioactive sources cantera is attached to the walls however, its features to shield $\mathrm{x}-\mathrm{or}-\gamma$ photons are unknown; therefore in facilities with cantera hosting $\mathrm{x}$ ray units or $\gamma$-ray sources the cantera is not accounted for shielding design or to evaluate the shielding effectiveness.

The aim of this work was to estimate the shielding characteristics of cantera using Monte Carlo methods and the XCOM code [27] for 0.03, 0.07, 0.1, 0.3, 0.662, 1, 2, and $3 \mathrm{MeV}$ mono-energetic photons. The relative transmission of Kerma in air, $\mathrm{Ka}$, and the Ambient dose equivalent, $H^{*}(10)$, was also determined.

For $0.662 \mathrm{MeV}$ photons the calculated $\mu$ was compared with the $\mu$ measured using a $\mathrm{NaI}(\mathrm{Tl})$-based $\gamma$ ray spectrometer and a ${ }^{137} \mathrm{Cs}$ source.

\section{Materials and methods}

From the local market a large piece of cantera was purchased and it was cut in $10 \times 10 \mathrm{~cm}$ pieces with different thickness, ranging from 1 up to $40 \mathrm{~cm}$. Each piece was weighted to determine the density, being $1.8 \pm$ $2 \% \mathrm{~g} \mathrm{~cm}^{-3}$.

From the large piece of cantera several samples were taken in order to measure the chemical composition using Energy Dispersive X-ray Fluorescence. Cantera is mainly composed by $\mathrm{SiO}_{2}, \mathrm{Al}_{2} \mathrm{O}_{3}, \mathrm{~K}_{2} \mathrm{O}, \mathrm{Na}_{2} \mathrm{O}, \mathrm{Fe}_{2} \mathrm{O}_{3}$, and $\mathrm{CaO}$, being in agreement with the chemical composition reported by Celik and Ergul [28]. Due to the total alkali $\left(\mathrm{Na}_{2} \mathrm{O}+\mathrm{K}_{2} \mathrm{O}\right)$ versus silica $\left(\mathrm{SiO}_{2}\right)$ composition, this cantera tuff is Rhyolite [28, 29].

\subsection{Calculations}

The chemical composition of cantera was used to calculate the elemental concentration in weight fraction, being: Oxygen $(0.4604 \mathrm{w} / \mathrm{o})$, Silicon $(0.2476 \mathrm{w} / \mathrm{o})$, Aluminium $(0.1022 \mathrm{w} / \mathrm{o})$, Carbon $(0.0651 \mathrm{w} / \mathrm{o})$, Iron (0.0509 w/o), Potassium (0.0459 w/o), Sodium (0.0156 w/o), Magnesium (0.0074 w/o), and Calcium (0.0049 w/o). The elemental concentration was used to calculate the shielding features against photons using the XCOM and the Monte Carlo code MCNP5 [30].

\subsubsection{XCOM}

The XCOM code uses a large data base with Coherent scattering, Compton scattering (Incoherent scattering), Photoelectric absorption, and Pair production cross sections for several elements.

The chemical composition of cantera was input in the XCOM code and the mass interaction coefficients and the total mass attenuation coefficients, for $1 \mathrm{keV}$ to $100 \mathrm{GeV}$ photons, were calculated. The mass attenuation coefficient is calculated using equation 1.

$$
\left(\frac{\mu}{\rho}\right)=\sum_{i} w_{i}\left(\frac{\mu}{\rho}\right)_{i}
$$

In equation $1, \rho$ is the cantera density, and $\mathrm{w}_{\mathrm{i}}$ and $(\mu / \rho)_{i}$ are the weight fractions and mass attenuation coefficient of the constituent element i respectively.

The density of cantera and the total mass attenuation coefficients were used to calculate the linear attenuation coefficient, $\mu$, for photons of $0.03,0.07,0.10,0.3,0.662$, 1, 2 and $3 \mathrm{MeV}$, using equation 2 .

$$
\mu(E)=\rho\left(\frac{\mu}{\rho}\right)(E)
$$

Here, $\mu(E)$ is the linear attenuation coefficient of cantera for photons of $\mathrm{E} \mathrm{MeV}, \rho$ is the density of cantera, and $(\mu / \rho)(E)$ is the mass attenuation coefficient of cantera for photons of $\mathrm{E} \mathrm{MeV}$.

\subsubsection{MCNP5}

In the MCNP5 calculations a model of a transmission experiment was built. Here, a point-like and isotropic photon source was used where the source term was mono-energetic, with photons of $30,70,100$, and 300 $\mathrm{keV}$ in order to cover the $\mathrm{x}$-rays for diagnosis, and 0.662 , 1, 2 and $3 \mathrm{MeV}$ to include gamma-ray sources.

A point-like detector was placed $42 \mathrm{~cm}$ from the source, between the source and the detector models of the cantera pieces where included. Calculations were carried out for $0,0.5,1,2, \ldots, 39,40 \mathrm{~cm}$-thick cantera pieces. The f5 tally was used to estimate the collided (total) and the uncollided photon fluence.

The uncollided photon fluence and the cantera thickness were fitted to the exponential function in order to calculate the linear attenuation coefficients that were compared with the $\mu$ calculated with the XCOM code.

The MCNP5 calculations also included the Kerma in air, $\mathrm{Ka}$, and the Ambient dose equivalent, $\mathrm{H}^{*}(10)$ that were calculated using the ICRP 74 [31] fluence-to-dose conversion coefficients. For each case the amount of histories used in the Monte Carlo calculations was large enough to have an uncertainty less than $5 \%$. 


\subsection{Measurements}

Using a $555 \pm 5 \% \mathrm{MBq}{ }^{137} \mathrm{Cs}$ source in a lead shield with a $1 \mathrm{~cm}$-diameter collimator, a transmission experiment was carried out using a narrow geometry array.

The transmitted photon spectrum was measured with gamma-ray spectrometer with a $7.62 \varnothing \times 7.62 \mathrm{~cm} \mathrm{NaI}(\mathrm{Tl})$ detector and a multichannel analyser. The detector was sited in a lead shield with $1 \mathrm{~cm}$-diameter collimator. The centres of both collimators were aligned.

The area under the $0.662 \mathrm{MeV}$ photopeak was measured as the cantera pieces with different thickness were placed between the source and the detector. The live-time of measurements was set to get $1 \%$ uncertainty in the photopeak net area.

For each cantera thickness the net count rates under the 0.662 photopeak were corrected due to background. Corrected count rates were normalized to the count rate measured without cantera and adjusted to an exponential function using the weighted regression [32]. The weight factors, $\omega$, were calculated using equation 3 .

$$
\omega_{i}=\frac{1}{s c_{i}+s x_{i}}
$$

Here, $\mathrm{sc}_{\mathrm{i}}$ is the variance of count rates measured with the $\mathrm{i}$-th cantera piece, $\mathrm{sx}_{\mathrm{i}}$ is the variance of the $\mathrm{i}$-th cantera thickness.

\section{Results}

\subsection{Calculations}

\subsubsection{XCOM results}

The cantera mass interaction coefficients, for $1 \mathrm{keV}-100$ $\mathrm{GeV}$ photons, calculated with the XCOM code, are shown in figure 1 .

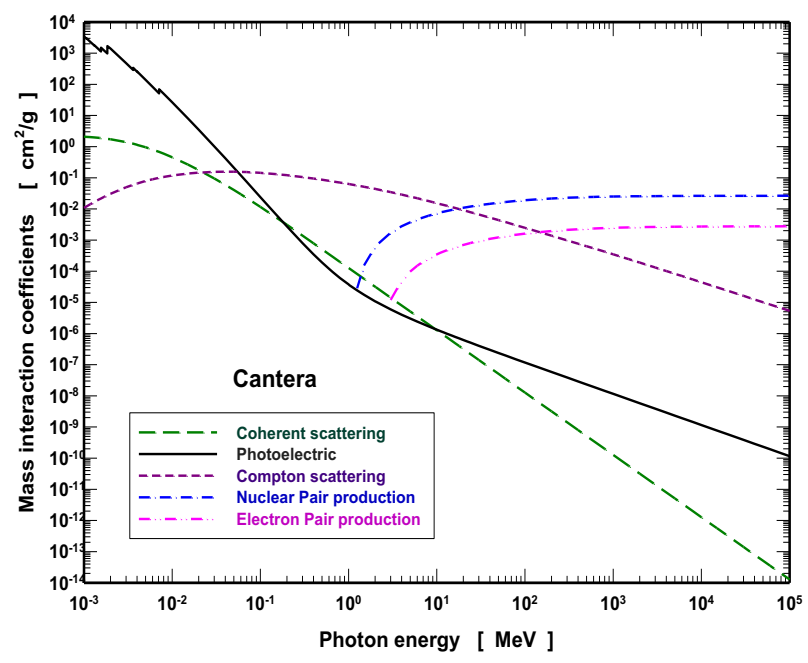

Figure 1. Photon mass interaction coefficients in cantera.
The interaction coefficients include coherent and incoherent (Compton) scattering, photoelectric effect, as well as, nuclear and electron pair production.

In cantera the photoelectric absorption is the main interaction mechanism for photons less than $60 \mathrm{keV}$, the best shielding performance is for low energy photons. For photons from $60 \mathrm{keV}$ to approximately $20 \mathrm{MeV}$ Compton scattering is the main interaction process with cantera where scattered photon, with lower energy, are produced.

The total mass attenuation coefficients of cantera for $10^{-3}$ to $10^{5} \mathrm{MeV}$ photons, are shown in figure 2 .

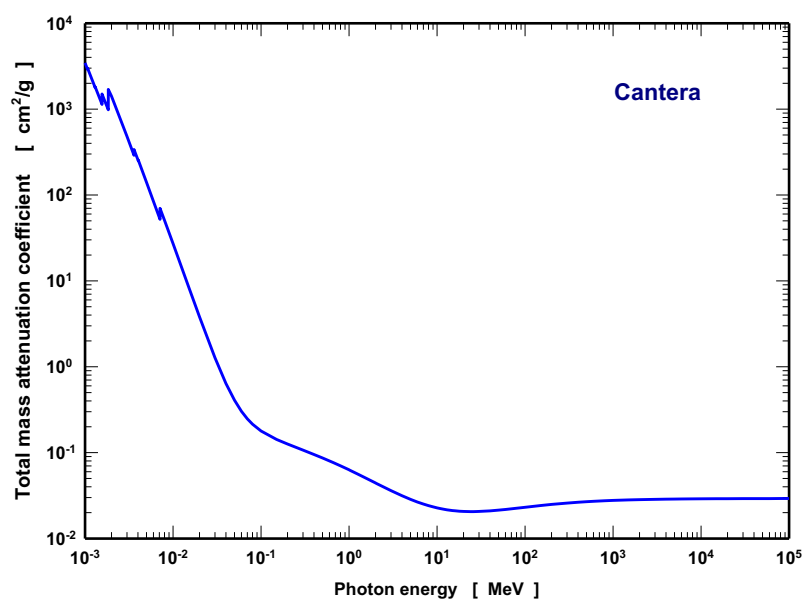

Figure 2. Total mass attenuation coefficients of cantera.

The total mass attenuation coefficients decreases sharply in the low energy region were discrete, small size, peaks appears. This behaviour is similar to the total mass attenuation coefficients reported for building materials [3]. In the low energy region there are seven resonances due to $\mathrm{K}$ absorption edge in $\mathrm{Na}, \mathrm{Mg}, \mathrm{Al}, \mathrm{Si}$, $\mathrm{K}, \mathrm{Ca}$, and $\mathrm{Fe}$.

Using the mass attenuation coefficients and the density of cantera the linear attenuation coefficients for $0.03,0.07,0.1,0.3,0.662,1,2$ and $3 \mathrm{MeV}$ photons were calculated being included in Table 1 .

Table 1. Linear attenuation coefficients of cantera.

\begin{tabular}{|c|c|c|}
\hline $\begin{array}{c}\text { Photon energy } \\
{[\mathbf{M e V}[}\end{array}$ & $\begin{array}{c}\boldsymbol{\mu}_{\mathbf{X C O M}} \\
{\left[\mathbf{c m}^{-1}\right]}\end{array}$ & $\begin{array}{c}\mu_{\text {MCNP5 }} \\
{\left[\mathbf{c m}^{-1}\right]}\end{array}$ \\
\hline 0.030 & 2.2895 & 2.2920 \\
\hline 0.070 & 0.4457 & 0.4455 \\
\hline 0.100 & 0.3218 & 0.3219 \\
\hline 0.300 & 0.1928 & 0.1926 \\
\hline 0.662 & 0.1380 & 0.1379 \\
\hline 1 & 0.1137 & 0.1135 \\
\hline 2 & 0.0798 & 0.0797 \\
\hline 3 & 0.0650 & 0.0649 \\
\hline
\end{tabular}




\subsubsection{Monte Carlo results}

In Figure 3 are shown the relative uncollided photon transmission, estimated with the MCNP5 code for monoenergetic photon sources in function of the mass thickness of cantera.

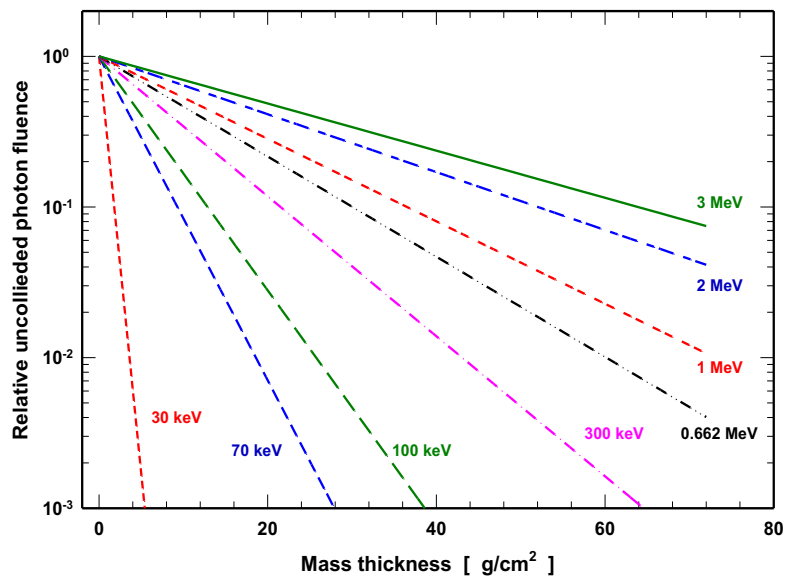

Figure 3. Uncollided photon transmission in cantera.

Data from Figure 3 were fitted into exponential functions and the linear attenuation coefficients were calculated.

In Table 1 are shown the $\mu$ values obtained with the XCOM and MCNP5 codes. There is a good agreement between the $\mu$ calculated using both codes.

The largest difference, noticed for $3 \mathrm{MeV}$ photons, was $0.27 \%$ being statistically insignificant. The Half value layer of cantera is $0.3,1.6,2.1,3.6,5.0,6.1,8.7$, and $10.7 \mathrm{~cm}$ for $0.03,0.07,0.1,0.3,0.662,1,2$, and 3 $\mathrm{MeV}$ photons respectively.

In Figure 4 the relative total photon (collided) transmission in cantera is shown.

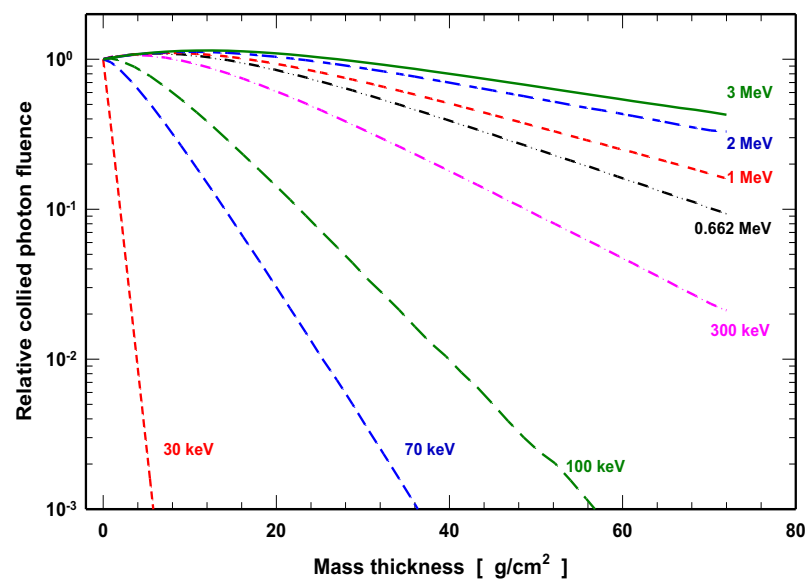

Figure 4. Collided photon transmission in cantera.

Total photon fluence includes the uncollided and the scattered photons. The differences between the photon transmission in figures 3 and 4 are due photon buildup in the detector. The photon buildup is the increase of photon fluence in the detector due to scattered photons by the cantera that reach the detector. Scattered photons have lower energies.

In Figure 5 the $\mathrm{Ka}$ transmission due to total photon fluence, in function of cantera mass thickness $(\mathrm{x} / \rho)$ for mono-energetic photons are presented. This feature is shown in terms of $(\mathrm{x} / \rho)$ because the density of cantera tuffs varies from 1.80 to $2.37 \mathrm{~g} \mathrm{~cm}^{-3}$ [22].

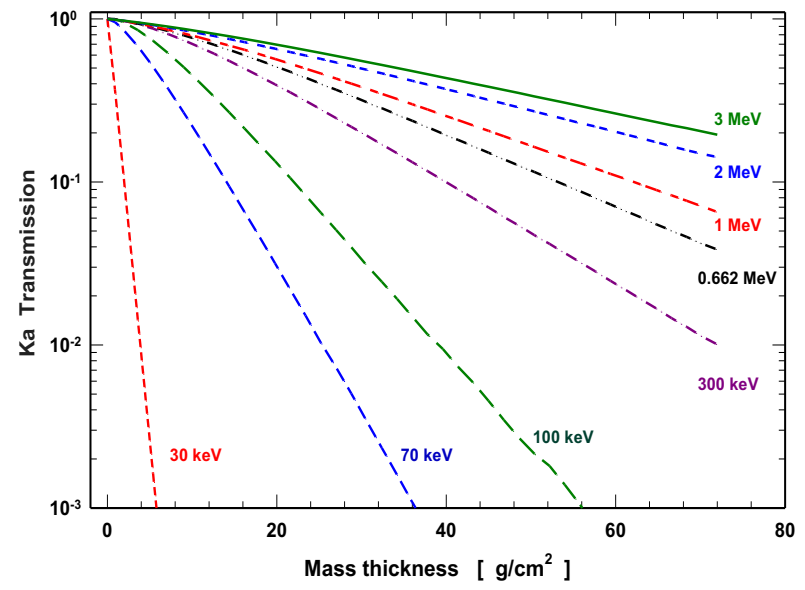

Figure 5. Kerma in air transmission in cantera.

The Ambient dose equivalent transmission of monoenergetic photons in cantera is shown in Figure 6.

Despite the fluence-to- $\mathrm{H}^{*}(10)$ conversion coefficients are larger than the fluence-to-Ka conversion coefficients for photons from 0.03 to $3 \mathrm{MeV}$ [31], for the same thickness of cantera the $\mathrm{H}^{*}(10)$ transmission is slightly larger than $\mathrm{Ka}$ transmission. The probable explanation is because $H^{*}(10)$ and the Ka values were calculated using collided photons (uncollided and scattered) that reach the detector, therefore some scattered photons has energies where fluence-to-Ka conversion coefficients are larger than fluence-to- $\mathrm{H}^{*}(10)$ conversion coefficients.

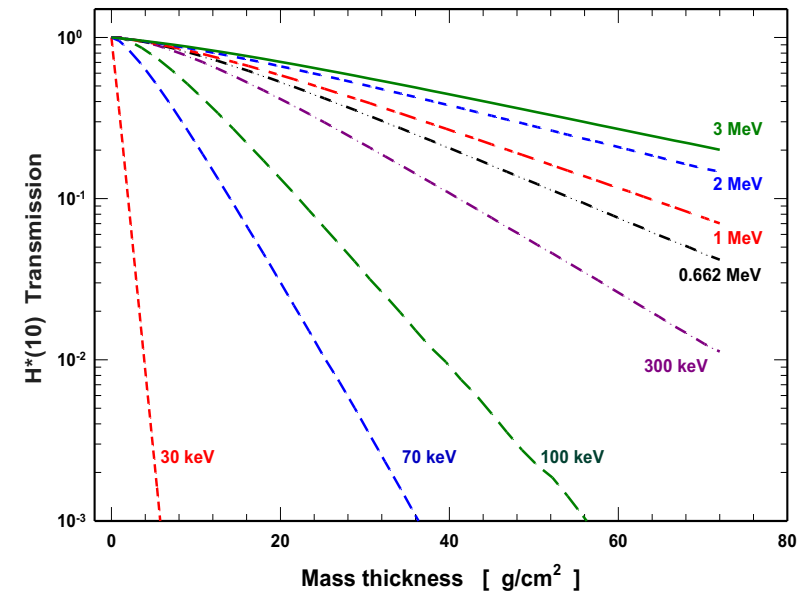

Figure 6. Ambient dose equivalent transmission in cantera.

\subsection{Measurements}

The linear attenuation coefficient of cantera for 0.662 $\mathrm{MeV}$ photons from ${ }^{137} \mathrm{Cs}$ source is $0.14 \pm 0.01 \mathrm{~cm}^{-1}$. This 
value was obtained through measurements carried out with the $\mathrm{NaI}(\mathrm{Tl}) \gamma$-ray spectrometer. The measured $\mu$ is in agreement with the $\mu$-values for $0.662 \mathrm{MeV}$ photons calculated with XCOM and MCNP5 codes, shown in Table 1.

The $\mu / \rho$ for $0.662 \mathrm{MeV}$ is $0.076 \mathrm{~cm}^{2} \mathrm{~g}^{-1}$ being similar to the value shown in building materials [2] and is larger than $\mu / \rho$ of aluminium $\left(7.466 \times 10^{-2} \mathrm{~cm}^{2} \mathrm{~g}^{-1}\right)$ and smaller than $\mu / \rho$ of lead $\left(0.1101 \mathrm{~cm}^{2} \mathrm{~g}^{-1}\right)$ [33].

\section{Conclusions}

The cantera is widely used in the construction industry however, it's shielding features against $\mathrm{x}$ and $\gamma$-rays were unknown. Through calculations with XCOM and MCNP5 codes the shielding features of cantera have been estimated for $0.03,0.07,0.100,0.300,0.662,1,2$, and 3 $\mathrm{MeV}$ monoenergetic photons. Using a ${ }^{137} \mathrm{Cs}$ and a NaI(Tl) $\gamma$-ray spectrometer the linear attenuation coefficient for $0.662 \mathrm{MeV}$ photons was also measured.

Due to total alkali and silica content in this quarry tuff is defined as rhyolite having a density of $1.8 \mathrm{~g} \mathrm{~cm}^{-3}$.

Linear attenuation coefficient of cantera varies from approximately 2.290 to $0.065 \mathrm{~cm}^{-1}$ for $30 \mathrm{keV}$ to $3 \mathrm{MeV}$ photons respectively.

For $30 \mathrm{keV}$ photons the half value layer of cantera is $0.3 \mathrm{~cm}$ and $10.7 \mathrm{~cm}$ for $3 \mathrm{MeV} \gamma$-rays.

Photons with energy less than $60 \mathrm{keV}$ are effectively shielded because the main interaction with cantera is through photoelectric interaction. Thus, the cantera is a good shielding material for rooms with x-ray units working below $60 \mathrm{kV}$. This $\mathrm{x}$-ray equipment includes radio diagnostic $\mathrm{x}$-rays for mammography or some few used for dental radiographies.

For photons with energy between $60 \mathrm{keV}$ and $10 \mathrm{MeV}$ the main interaction in cantera is Compton scattering. Here, the energy of the incoming photon is reduced, but scattered photons contribute with the photon and the dose build up that should be evaluated. Nevertheless in rooms with x-ray units working above $60 \mathrm{kV}$, like dental, diagnosis, interventional $\mathrm{x}$-rays, or those with $\gamma$-ray sources, the cantera in the walls will help to shield photons and to reduce the dose.

For the same thickness of cantera the $\mathrm{Ka}$ and $\mathrm{H}^{*}(10)$ transmission is almost the same.

A limitation of this work was the use of monoenergetic photons to represent x-rays, because x-ray tubes produce photons with a wide and continuous energy distribution together with few discrete peaks where just quite few photons have the largest energy. However, if the information here presented is used to calculate a shielding made with cantera will be conservative because the photon mean energy of actual x-rays is smaller than the energy of photons here used.

Another limitation of this work was that photons and dose buildup factors for cantera were not included.

\section{References}

1. V. P. Singh, N. M. Badiger and A. M. El-Khayatt, Radiat. Eff. Def. Solids 169, 547 (2014)

2. K. S. Mann, B. Kaur, G. S. Sidhu, A. Kumar, Radiat. Phys. Chem. 87, 16 (2013)

3. Ch. Singh, T. Singh, A. Kumar, G. S. Mudahar, Ann. Nucl. Energy 31, 1199 (2004)

4. B. Oto, N. Yildiz, F. Akdemir, E. Kavaz, Prog. Nucl. Energy 85, 391 (2015)

5. S. Kaewjang, U. Maghanemi, S. Kothan, H. J. Kim, P. Limkitjaroenporn and J. Kaewkhao, Nucl. Eng. Des. 280, 21 (2014)

6. Y. Gedikoglu, G. Gedikoglu, G. Berkin, T. Ceyhan, M. A. Altinoz, Toxicol. Ind. Health 28, 708 (2012)

7. K. S. Mann, A. Rani and M. S. Heer, Rad. Phys. Chem. 106, 247 (2015)

8. J. Miller, L. Taylor, C. Zeitlin, L. Heilbronn, S. Guetersloh, M. DiGiuseppe, Y. Iwata, T. Murakami, Radiat. Meas. 44, 163 (2009)

9. T. Korkut, H. Korkut, A. Karabulut, G. Budak, Ann. Nucl. Energy 38, 56 (2011)

10. V. P. Singh, N. M. Badiger, Vacuum, 113, 24 (2015)

11. D. N. Hopkins, M. Maqbool, M. S. Islam, Radiol. Phys. Technol. 5, 229 (2012)

12. J. Kim, D. Seo, B. Ch. Lee, Y. S.Seo, W. H. Miller, Adv. Engr. Mat. 16, 1083 (2014)

13. E.-S. A. Waly, M. A. Bourham, Ann. Nucl. Energy 85, 306 (2015)

14. I. I. Bashter, Ann. Nucl. Energy 24, 1389 (1997)

15. I. Akkurt, H. Akyildirim, B. Mavi, S. Kilincarslan, C. Basygit, Ann. Nucl. Energy 37, 910 (2010)

16. A. M. El-Khayatt, Ann. Nucl. Energy 37, 991 (2010)

17. E. Gallego, A. Lorente and H. R. Vega-Carrillo, Nucl. Tech. 162, 399 (2009)

18. T. Piotrowski, D. B. Tefelski, J. J. Sokolowska, B. Jaworska, Acta Phys. Pol. A 128, B-9 (2015)

19. T. Piotrowski, D. B. Tefelski, J. Skubalski, A. Zak, Acta Phys. Pol. A 128, B-14 (2015)

20. P. Ciccioli, P. Plescia, D. Capitani, J. Phys. Chem. C 114, 9328 (2010)

21. P. Yasaka, N. Pattanaboonmee, H. J. Kim, P. Limkitjaroenpron, J. Kaewkaho, Ann. Nucl. Energy 68, 4 (2014)

22. R. López-Doncel, W. Wedekind, T. Leiser, S. Molina-Maldondo, A. Velasco-Sánchez, R. Dohrmann, A. Kral, A. Wittenborn, A. AguillónRobles, S. Siegesmund, Environ. Earth Sci. 75, 212 (2016)

23. W. Wedekind, R. López-Doncel, R. Dohrmann, M. Kocher, S. Siegesmund, Environ. Earth Sci. 69, 1203 (2013)

24. M. Degerlier, Radioprotection 48, 215 (2013)

25. S. Turhan, E. Atici, A. Varinlioglu, Radioprotection 50, 273 (2015) 
26. N. A. Pérez, E. Lima, P. Bosch, J. Méndez-Vivar, J. Cult. Herit. 15, 352 (2014)

27. M. J. Berger, J. H. Hubbell, S. M. Seltzer, J. Chang, J. S. Coursey, R. Sukumar, D. S. Zucker, K. Olsen, XCOM: Photon Cross Sections Database, version 1.5, [Online]. <http://physics.nist.gov/pml/data/xcom /data/xcom/index.cfm $>$. Gaithersburg, MD, USA.

28. M. Y. Celik, A. Ergul, Environ. Earth Sci. 74, 3223 (2015)

29. M. J. Le Bas, R. W. Le Maitre, A. R. Woolley, Miner. Pet. 46, 1 (1992)

30. X-5 Monte Carlo Team, Report LA-UR-03-1987 Los Alamos National Laboratory (2003)

31. ICRP74, Ann. ICRP 26, 179 (1996)

32. H. R. Vega-Carrillo, Rev. Mex. Fis. 35, 597 (1989)

33. T. E. Johnson. B. K. Birky, Health Physics and Radiological Health (Lippincott Williams \& Wilkins, 2012) 